\title{
Photoluminescence Study of the Influence of Additive Ammonium Hydroxide in Hydrothermally Grown ZnO Nanowires
}

\author{
A. S. Dahiya ${ }^{1 *}$ D, S. Boubenia ${ }^{1}$, G. Franzo ${ }^{2}$, G. Poulin-Vittrant ${ }^{3}$, S. Mirabella ${ }^{2}$ and D. Alquier ${ }^{1}$
}

\begin{abstract}
We report the influence of ammonium hydroxide $\left(\mathrm{NH}_{4} \mathrm{OH}\right)$, as growth additive, on zinc oxide nanomaterial through the optical response obtained by photoluminescence (PL). A low-temperature hydrothermal process is employed for the growth of $\mathrm{ZnO}$ nanowires (NWs) on seedless Au surface. A more than two order of magnitude change in $\mathrm{ZnO}$ NW density is demonstrated via careful addition of $\mathrm{NH}_{4} \mathrm{OH}$ in the growth solution. Further, we show by systematic experimental study and $\mathrm{PL}$ characterization data that the addition of $\mathrm{NH}_{4} \mathrm{OH}$ can degrade the optical response of $\mathrm{ZnO}$ NWs produced. The increase of growth solution basicity with the addition of $\mathrm{NH}_{4} \mathrm{OH}$ may slowly degrade the optical response of NWs by slowly etching its surfaces, increasing the point defects in ZnO NWs. The present study demonstrates the importance of growth nutrients to obtain quality controlled density tunable $\mathrm{ZnO}$ NWs on seedless conducting substrates.
\end{abstract}

Keywords: Zinc oxide, Nanowires, Hydrothermal, Photoluminescence, Ammonium hydroxide

\section{Background}

Significant developments in the synthesis of functional nanomaterials via bottom-up approaches are now offering high-quality materials for the development of next-generation efficient electronic devices [1-5]. The ZnO's field of research has shown resurgence in interest after the successful demonstration of the growth of single-crystalline nanostructures (nanobelt) [6]. Thereafter, the use of high-quality, single-crystalline semiconducting $\mathrm{ZnO}$ nanostructures for the assembly of high-performance electronics continues to attract enormous research interest in the field of displays [7, 8], logic circuits [9, 10], sensors [11, 12], and optoelectronics [13]. The renewal of interest in $\mathrm{ZnO}$ material has largely been driven by its bio-compatibility, facile nanostructure fabrication, and large family of achievable nanomorphologies $[14,15]$. Among the various different $\mathrm{ZnO}$ nanoarchitectures, one-dimensional (1D) $\mathrm{ZnO}$ nanowires (NWs) and nanorods (NRs) have been investigated comprehensively as an active semiconducting material in

\footnotetext{
* Correspondence: abhishek.dahiya@univ-tours.fr

${ }^{1}$ GREMAN UMR 7347 Université de Tours, CNRS, INSA Centre Val de Loire, 16 rue Pierre et Marie Curie, 37071 Tours CEDEX2, France

Full list of author information is available at the end of the article
}

nanoscale devices such as field-effect transistors (FETs) [16], nanogenerators (NGs) [17], or sensors [12].

Ideally, a well stoichiometric $\mathrm{ZnO}$ is an insulator. However, in its non-stoichiometric form, it can behave as semiconductor or conductor depending on the number of native point defects created and/or by amount of dopant introduced. It has been shown that, in nanostructured $\mathrm{ZnO}$, defects play a central role in defining the electronic device performances, as for sensors [18] and/or nanogenerators $[17,19]$, by controlling free charge density, minority carrier life time, and luminescence efficiency. For instance [18], it has been shown that highly sensitive UV sensors can be obtained by increasing the number of surface defects in $\mathrm{ZnO}$ NWs. These surface defects may act as trapping centers for free electrons and results in the formation of surface depletion layer. The greater the depth of depletion region at the NW surface, the higher the UV sensitivity. On the other hand, a too large number of defects have detrimental effects on the NG device performances $[17,19]$. Therefore, a perfect control over the quality of $\mathrm{ZnO}$ nanomaterial produced is essential to build a high-performance electronic device.

Different bottom-up growth techniques, including flame transport approach [20-23], vapor-liquid-solid (VLS) [24], 
electrochemical deposition [25], and hydrothermal and/or chemical bath deposition [16, 26-29] have been utilized for the synthesis of $1 \mathrm{D} \mathrm{ZnO} \mathrm{NWs.} \mathrm{Nevertheless,} \mathrm{most} \mathrm{of}$ the techniques are limited by their high-temperature process that cannot be scaled up over large device area at very low cost, on plastic substrates for example. The need of a facile, industrially scalable, and substrate-independent synthesis of $\mathrm{ZnO} \mathrm{NWs}$ has seen significant advancements towards the hydrothermal growth process $[16,17]$. Hydrothermal growth (HTG) is a low-temperature process where single-crystalline 1D material can be produced on various substrates, including plastics or even textile fibers [30]. In general, HTG-grown $\mathrm{ZnO} \mathrm{NWs}$ show intense defect level band peak in photoemission spectra which expands from blue to red color wavelength emission depending on type of defects in the nanomaterial [31]. In the literature, many different point defects such as oxygen and zinc vacancies $\left(\mathrm{V}_{\mathrm{O}}\right.$ and $\left.\mathrm{V}_{\mathrm{Zn}}\right)$ and interstitial $\left(\mathrm{O}_{\mathrm{i}}\right.$ and $\left.\mathrm{Zn}_{\mathrm{i}}\right)$, antisites $\left(\mathrm{O}_{\mathrm{Zn}}\right.$ and $\left.\mathrm{Zn}_{\mathrm{O}}\right)$, and hydrogen impurities were identified to be the cause of the defect level emission band in photoluminescence (PL) [32]. The visible PL band consists of three Gaussian components at 2.52, 2.23, and $2.03 \mathrm{eV}$, respectively labeled as blue $\mathrm{I}_{\mathrm{B}}$, green $\mathrm{I}_{\mathrm{G}}$, and orange $\mathrm{I}_{\mathrm{O}}$ peak emission [33]. However, even after years of investigations, the origin of these defect states is still a subject of debate. Nevertheless, irrespective of the cause of defects in $\mathrm{ZnO}$, the ratio of the band-to-band transition (UV emission) to the defect-related peak intensity in PL spectrum predicts the optical response of the nanomaterial produced $[18,34]$.

Growth process with an in situ integration of $\mathrm{ZnO}$ NWs over a metal electrode without any $\mathrm{ZnO}$ seed layer may improve the charge transport process across the metal-semiconductor (MS) contact interface and, in consequence, may improve device performances [35]. Ammonium hydroxide $\left(\mathrm{NH}_{4} \mathrm{OH}\right)$ has often been employed for the growth of $\mathrm{ZnO}$ NWs on Au metal surfaces $[35,36]$. For instance, in our previous work, we show that $\mathrm{NH}_{4} \mathrm{OH}$ can be used for simultaneous tuning of the NW density and electrical properties of the $\mathrm{ZnO}$ NWs grown on seedless Au surface [5]. However, report detailing the effect of the addition of $\mathrm{NH}_{4} \mathrm{OH}$ over the optical response of the produced $\mathrm{ZnO}$ nanomaterial on $\mathrm{Au}$ surface is rarely found in literature. In the present report, we study the $\mathrm{ZnO}$ material optical response by analyzing the defect-related emission and UV emission in PL spectrum of NWs grown in different $\mathrm{NH}_{4} \mathrm{OH}$ concentrations. Two dominant peaks, noticed in the PL graph, are centered at $3.24 \mathrm{eV}(382 \mathrm{~nm})$ and $2.23 \mathrm{eV}$ $(556 \mathrm{~nm})$, respectively referred as ultraviolet (UV) emission $\left(\mathrm{I}_{\mathrm{UV}}\right)$ and green defect level emission $\left(\mathrm{I}_{\mathrm{G}}\right)$ peaks. The extracted ratio $\mathrm{I}_{\mathrm{UV}} / \mathrm{I}_{\mathrm{G}}$ provides a qualitative index of the radiative defect amount in the produced nanomaterial. The effect of $\mathrm{NH}_{4} \mathrm{OH}$ is further confirmed by carrying out another series of experiments and PL characterizations. In this second series of experiments, we have grown $\mathrm{ZnO} \mathrm{NWs}$ without $\mathrm{NH}_{4} \mathrm{OH}$ and, then, carried out a post-growth treatment of NWs in ammonia solution with different $\mathrm{pH}$. We found out a similar trend of decrease in the ratio $\mathrm{I}_{\mathrm{UV}} / \mathrm{I}_{\mathrm{G}}$ for both series of samples, i.e., the ones grown in different $\mathrm{NH}_{4} \mathrm{OH}$ concentration and the other ones post-growth treated in $\mathrm{NH}_{4} \mathrm{OH}$.

\section{Methods}

The $\mathrm{ZnO}$ NWs are grown by hydrothermal growth process on (100) oriented Si wafers. A sample of $2 \times$ $2 \mathrm{~cm}^{2}$ rigid silicon is first cleaned in piranha solution (1:1 $\mathrm{H}_{2} \mathrm{SO}_{4}$ and $\mathrm{H}_{2} \mathrm{O}_{2}$ ) for $10 \mathrm{~min}$ followed by a 2-min dip in hydrofluoric acid (50\%) to remove the thin oxide formed during piranha cleaning and, finally, rinsing in deionized (DI) water. This cleaning step is followed by drying with nitrogen gas, and a final baking step is performed at $\sim 200{ }^{\circ} \mathrm{C}$ to remove any adsorbed moisture before the metal deposition. A gold layer ( $200 \mathrm{~nm}$ thick) is then deposited by direct current sputtering technique at room temperature. To improve the adhesion between gold and silicon, we deposit a layer of titanium ( $100 \mathrm{~nm}$ ) using the same technique. The reactant precursor for HTG consists of 1:1 ratio of zinc nitrate hexahydrate $\left(\mathrm{Zn} \quad\left(\mathrm{NO}_{3}\right)_{2}, 6 \mathrm{H}_{2} \mathrm{O}, 98 \%\right.$ Sigma Aldrich $)$ and hexamethylenetetramine (HMTA, Sigma Aldrich). During the growth, the substrates were immersed facing down in a Teflon cup, sealed inside stainless steel autoclave reactor and placed in a preheated convection oven at $85{ }^{\circ} \mathrm{C}$ for $15 \mathrm{~h}$. The autoclave is taken out from the oven and cools down naturally. The substrates are then thoroughly rinsed with flowing DI water and dried in $\mathrm{N}_{2}$ gas flow. In the experiments, the concentration of $\mathrm{NH}_{4} \mathrm{OH}$ is varied from 0 to $50 \mathrm{mM}$. A Hitachi $\mathrm{S}-4150$ scanning electron microscope (SEM) system is used for the morphological characterization of the ZnO NWs. To follow up the optical response of the obtained NWs with different $\mathrm{NH}_{4} \mathrm{OH}$ concentrations, photoluminescence (PL) measurements were performed; at room temperature (RT), by pumping at $1.5 \mathrm{~mW}$, the $325 \mathrm{~nm}$ line of a $\mathrm{He}-\mathrm{Cd}$

\begin{tabular}{|c|c|c|c|c|}
\hline $\begin{array}{l}\text { S. } \\
\text { no. }\end{array}$ & $\begin{array}{l}\text { Zinc nitrate and HMTA } \\
\text { concentration (mM) }\end{array}$ & $\begin{array}{l}\mathrm{NH}_{4} \mathrm{OH} \\
\text { concentration } \\
\text { (mM) }\end{array}$ & $\mathrm{pH}$ & $\begin{array}{l}\text { Growth } \\
\text { time (h) }\end{array}$ \\
\hline 1 & 100 & 0 & 6.6 & 6 \\
\hline 2 & 100 & 10 & 6.7 & 6 \\
\hline 3 & 100 & 20 & 6.8 & 6 \\
\hline 4 & 100 & 30 & 6.9 & 6 \\
\hline 5 & 100 & 40 & 7.0 & 6 \\
\hline 6 & 100 & 50 & 7.1 & 6 \\
\hline
\end{tabular}



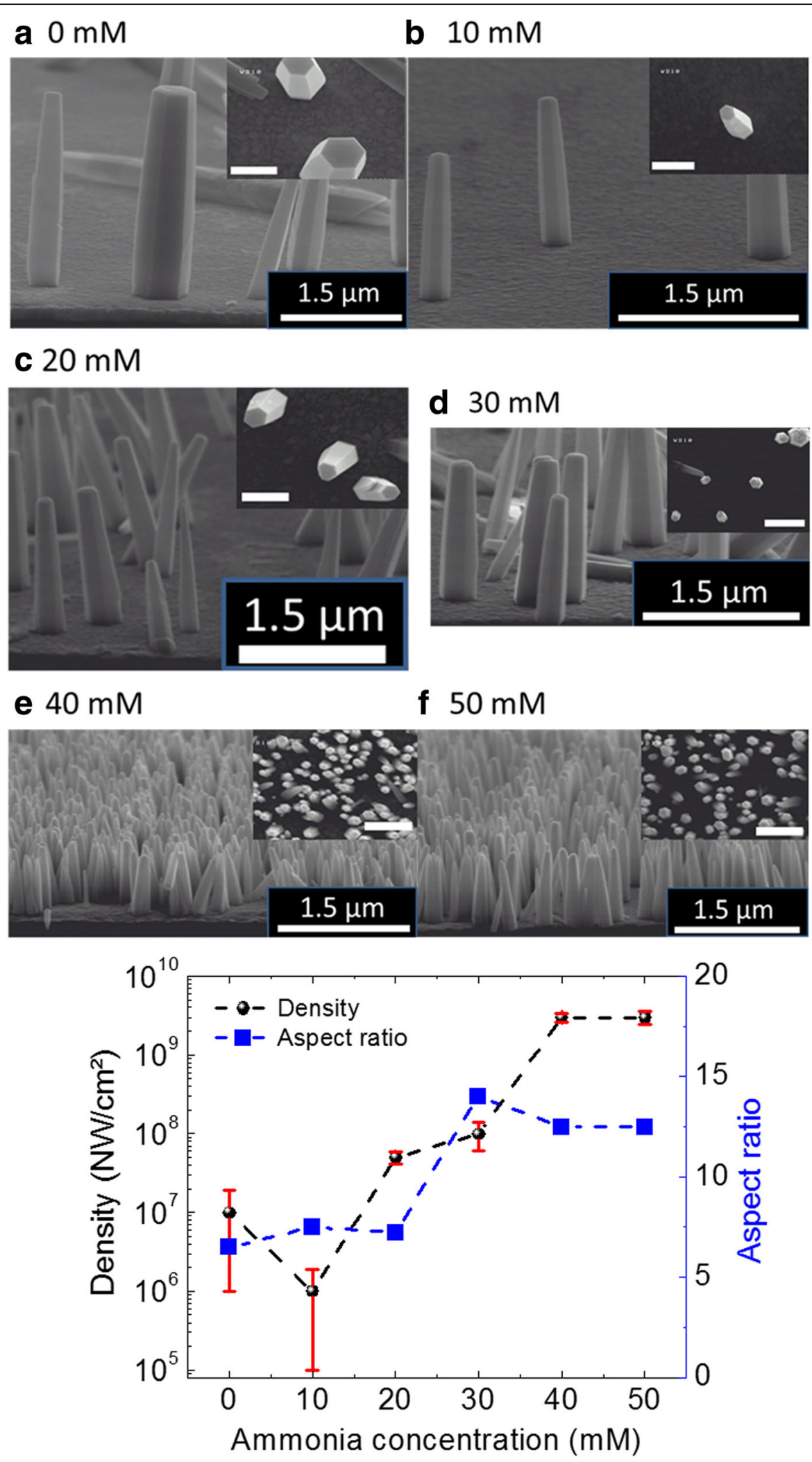

Fig. 1 SEM images of NWs grown for different concentrations of ammonia. a 0 mM, b 10 mM, c 20 mM, d 30 mM, e 40 mM, and f 50 mM. The inset in each panel (a-e) shows the top-view SEM image acquired from the same sample. The scale bar in the inset is $500 \mathrm{~nm}$. $\mathbf{g}$ The variation of density and aspect ratio of NWs with the change in $\mathrm{NH}_{4} \mathrm{OH}$ concentration 
laser chopped through an acousto-optic modulator at a frequency of $55 \mathrm{~Hz}$. Further experimental details for PL measurements can be found in Ref [33].

\section{Results and Discussions}

To execute the present study, $\mathrm{ZnO} \mathrm{NWs}$ are grown using HTG process with different $\mathrm{NH}_{4} \mathrm{OH}$ concentration at $85{ }^{\circ} \mathrm{C}$. The growth process parameters are mentioned in Table 1, and further growth details can be found in Ref. Boubenia et al. [5]. The obtained growth results while varying $\mathrm{NH}_{4} \mathrm{OH}$ concentrations (from 0 to $50 \mathrm{mM}$ by step of $10 \mathrm{mM}$ ) in the growth solution are presented in Fig. 1a-f; showing typical cross-sectional and top-view SEM images acquired from the $\mathrm{ZnO}$ NW samples. A more than two orders of magnitude change in $\mathrm{NW}$ density is obtained by careful addition of $\mathrm{NH}_{4} \mathrm{OH}$ in the growth solution. The mechanism behind the NW density variation with $\mathrm{NH}_{4} \mathrm{OH}$ addition can be found in Boubenia et al. [5], where the authors hypothesized that the amount of ammonium hydroxide has a direct effect over the concentration of $\mathrm{Zn}$ (II) complexes which largely affects the $\mathrm{Zn}$ solubility in the solution. Consequently, the supersaturation of the growth solution can be controlled and so the number of nuclei over the substrate. Furthermore, going along with density, aspect ratio (AR) of the nanostructures greatly determines/ conditions their application in flexible electronics where high surface to volume ratios are needed for increased strain absorption. Moreover, numbers of surface defect states are directly proportional to the AR of the NWs which has direct impact over the optical response of the nanomaterial. Hence, variation in NW's AR, with increasing $\mathrm{NH}_{4} \mathrm{OH}$ concentration, is also calculated using SEM images. Figure $1 \mathrm{~g}$ shows a graph depicting the density and $\mathrm{AR}$ variation trend with the addition of $\mathrm{NH}_{4} \mathrm{OH}$ in the growth solution. It can be seen, by using Fig. 1g, that, as the $\mathrm{NH}_{4} \mathrm{OH}$ concentration increases, both NW density and $A R$ increase until the values saturate at ammonium hydroxide concentration of $40 \mathrm{mM}$. Room temperature Raman spectroscopy measurements, performed on $\mathrm{ZnO}$ NWs grown with different $\mathrm{NH}_{4} \mathrm{OH}$ concentrations, confirm the wurtzite crystal structure of the nanomaterial produced (Additional file 1: Figure S1) [5].

Figure $2 \mathrm{a}$ shows the PL spectra measured at RT for NWs grown with various ammonium hydroxide concentrations. The PL spectrum from $\mathrm{ZnO}$ NWs features two emission bands: a near-band-edge (NBE) light emission and a broad deep-level (visible) emission. The excitation energy used in the present study is $3.81 \mathrm{eV}$ ensuring carrier population of the conduction band minimum. The strong and narrow UV emission peak, centered at $3.24 \mathrm{eV}$ for all cases, results from merging of the various exciton-related emission near the band edge, including recombination of free excitons and its longitudinal
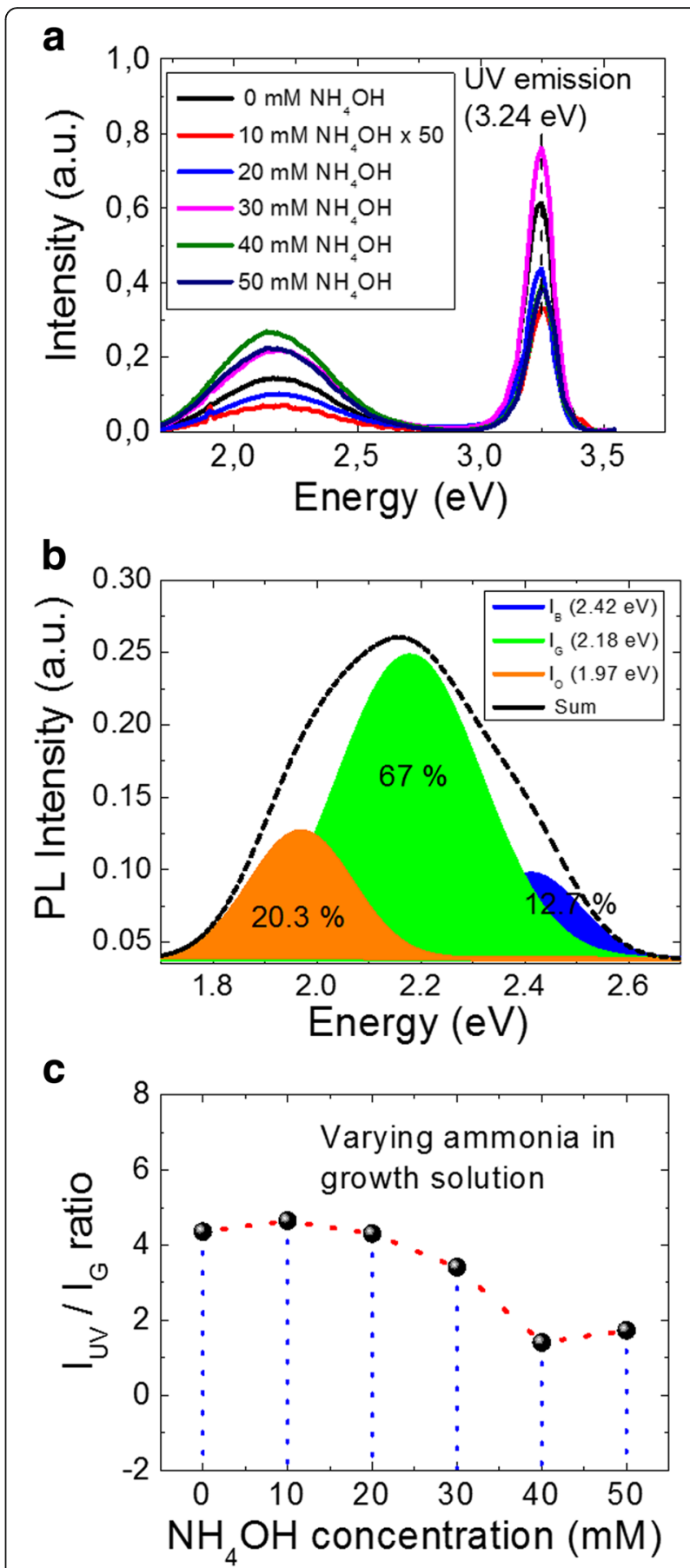

Fig. 2 The $P L$ measurements results. a The PL spectra of the $Z n O$ NWs grown under different ammonium hydroxide concentrations. $\mathbf{b}$ Deconvoluted Gaussian fit for the 40-mM sample to blue, green, and orange emission states and their percentage contributions in visible emission. c The intensity ratio of UV and green emission peak as a function of $\mathrm{NH}_{4} \mathrm{OH}$ concentration

optical (LO)-phonon replicas, [37] free-to-neutral acceptor transitions, [38] and donor-acceptor pair recombination [39], depending on the local lattice configuration and the presence of defects [40-42]. From Fig. 2a, we can 
also observe a broad visible level emission that expands from green to orange color wavelength. The presence of a broad visible emission peak may be explained with the hypothesis of existence of multiple defects and/or defect complexes which are dominantly present at the surface of $\mathrm{ZnO}$ nanostructures [34, 43]. However, in spite of a number of reports about the presence of visible emission in the $\mathrm{ZnO}$ 's PL spectrum, there is no clear consensus in the literature on the peak positions in the visible region or on their origin. It is also to note that, due to the large variation in density and aspect ratio from sample to sample (Fig. 1g), it is difficult to probe the same quantity of material for such different samples. Therefore, we cannot directly compare the emission intensity for these samples. Nevertheless, ratio of the magnitude of UV emission peak intensity with respect to defect-related peak intensity, in PL spectrum, predicts the optical response of the produced nanomaterial. All visible spectra can be successfully fitted by three defect-related visible luminescence states, namely blue, green, and orange. For instance, Fig. 2b plots the Gaussian fit of $40 \mathrm{mM} \mathrm{NH}_{4} \mathrm{OH}$ sample for the blue, green, and orange states, which are colored accordingly to emphasize their relative differences. It is to note here, although the PL intensity for both $\mathrm{UV}$ and visible emission peak varies due to difference in mass produced for varying $\mathrm{NH}_{4} \mathrm{OH}$ in solution, the percentage contribution for the blue, green, and orange states remains the same. In Fig. 2b, percentage contribution of each defect state, for the $40 \mathrm{mM}$ sample, is presented, showing the major contribution of visible emission is related to the green defect state. Therefore, to follow up the optical response of nanomaterial produced, it is fair to compare the intensity ratio of UV emission $\left(\mathrm{I}_{\mathrm{UV}}\right)$ to green defect state $\left(\mathrm{I}_{\mathrm{G}}\right)$, which appears to have highest percentage contribution in the visible spectra.

Figure 2c plots the extracted $\mathrm{I}_{\mathrm{UV}} / \mathrm{I}_{\mathrm{G}}$ ratio for each case of NWs grown with different ammonia concentrations, whereas Table 2 presents the extracted values. It can be seen, using Fig. 2c, that the $\mathrm{I}_{\mathrm{UV}} / \mathrm{I}_{\mathrm{G}}$ ratio decreases smoothly after $20 \mathrm{mM}$ of $\mathrm{NH}_{4} \mathrm{OH}$ in the growth solution. For instance, the $\mathrm{I}_{\mathrm{UV}} / \mathrm{I}_{\mathrm{G}}$ value for $40 \mathrm{mM}$ ammonia is three times lower than the one of "no ammonia" sample, indicating an increase of visible defect states with the addition of ammonia. Dominantly, there can be two possible reasons for the observed experimental increase of visible level defect states: (i) increase of the aspect ratio and (ii) increase of the solution basicity with the addition of ammonium hydroxide. Considering the first point, aspect ratio can greatly affect the intensity of visible level emission. For instance, Djurisic et al. performed in-depth $\mathrm{PL}$ analysis on $\mathrm{ZnO}$ nanostructures and concluded that green luminescence in $\mathrm{ZnO} \mathrm{PL}$ spectra probably originates from some non-paramagnetic defects or defect complexes and that the major part comes from surface defects [34]. It can be seen from Fig. 1g that there is a sharp increase of the aspect ratio $(L / d)$ above $20 \mathrm{mM}$ of $\mathrm{NH}_{4} \mathrm{OH}$ addition, where $L$ and $d$ are the length and diameter of the NW, respectively. A large AR signifies considerable increase of the surface to volume ratio, leading to enhanced defect level emission. Similar increase of the defect level emission with the increase of AR has been reported in Ref. [44] leading to a decrease in the $\mathrm{I}_{\mathrm{UV}} / \mathrm{I}_{\text {vis }}$ ratio. However, the authors are not convinced that the increase of AR can be the sole reason for the observed increase in defect emission intensity. They further pointed out that the obtained results can be very sensitive to the experimental conditions such as excitation density and radiation area [44].

Another possible reason to the observed increase in defect states in the NWs may be the addition of $\mathrm{NH}_{4} \mathrm{OH}$ itself. Chen et al. have shown that various defects can be induced in hydrothermally grown $\mathrm{ZnO}$ NWs (using $\mathrm{ZnO}$ seed layer) by the addition of $\mathrm{NH}_{3}$ molecules during the growth stage [45]. Although the addition of $\mathrm{NH}_{4} \mathrm{OH}$ is not crucial for the growth of $\mathrm{ZnO} \mathrm{NWs}$ using $\mathrm{ZnO}$ seed layer, for the seedless growth of $\mathrm{ZnO} \mathrm{NWs}$ on $\mathrm{Au}$ surfaces, the addition of $\mathrm{NH}_{4} \mathrm{OH}$ plays a key role in controlling the number of nucleation sites on Au surface. For example, Alenezi et al. explained the $\mathrm{ZnO}$ NW density variation on bare Au surface by stating that without $\mathrm{NH}_{4} \mathrm{OH}$, mainly $\mathrm{Zn}^{2+}$ ions are available, while using ammonium hydroxide they are limited which significantly lowers the rate of homogeneous nucleation and encourages the heterogeneous one. Similar observations are reported by Boubenia et al. [5], where more than two orders of NW density can be varied by careful control of

Table 2 Photoluminescence study of the influence of $\mathrm{NH}_{4} \mathrm{OH}$ addition over optical response of $\mathrm{ZnO}$ NWs

\begin{tabular}{|c|c|c|c|c|c|}
\hline S. no. & $\mathrm{NH}_{4} \mathrm{OH}$ concentration (mM) & IUV & $\mathrm{I}_{\mathrm{G}}$ & $I_{U V} / I_{G}$ & Free charge density $\left(/ \mathrm{cm}^{3}\right)[5]$ \\
\hline 1 & 0 & 0.61 & 0.14 & 4.4 & $4.3 \pm 3.9 \times 10^{16}$ \\
\hline 2 & 10 & 0.33 & 0.07 & 4.6 & N/A \\
\hline 3 & 20 & 0.43 & 0.1 & 4.3 & $8.3 \pm 4 \times 10^{16}$ \\
\hline 4 & 30 & 0.75 & 0.22 & 3.4 & N/A \\
\hline 5 & 40 & 0.38 & 0.27 & 1.4 & $2 \pm 1 \times 10^{17}$ \\
\hline 6 & 50 & 0.38 & 0.22 & 1.7 & N/A \\
\hline
\end{tabular}


Table 3 Experimental parameters for the post-growth treatment of NWs in different concentrations of ammonium hydroxide solution and their effect over the optical response of the $\mathrm{ZnO}$ nanomaterial as measured by photoluminescence

\begin{tabular}{|c|c|c|c|c|c|c|c|}
\hline S. no. & $\mathrm{NH}_{4} \mathrm{OH}$ concentration (mM) & $\mathrm{pH}$ & Time (min) & Temperature $\left({ }^{\circ} \mathrm{C}\right)$ & luv & $\mathrm{I}_{\mathrm{G}}$ & $I_{\cup V} / I_{G}$ \\
\hline 1 & As-grown & 6.6 & $\mathrm{~N} / \mathrm{A}$ & N/A & 0.61 & 0.14 & 4.4 \\
\hline 2 & 10 & 11.1 & 30 & 80 & 0.39 & 0.28 & 1.4 \\
\hline 3 & 40 & 11.5 & 30 & 80 & 0.33 & 0.24 & 1.37 \\
\hline 4 & 100 & 11.7 & 30 & 80 & 0.3 & 0.14 & 2.1 \\
\hline 5 & 200 & 11.9 & 30 & 80 & 0.16 & 0.13 & 1.2 \\
\hline
\end{tabular}

$\mathrm{NH}_{4} \mathrm{OH}$ concentration in the growth solution. Authors further claim an increase of free charge carrier density while field-effect mobility decreases as the $\mathrm{NH}_{4} \mathrm{OH}$ concentration increases, hinting the creation of extra point defects with the addition of $\mathrm{NH}_{4} \mathrm{OH}$ in the growth solution. However, no PL data is shown to confirm the reported electrical results. The PL results shown in Fig. 2 are in complete agreement with the electrical results reported by Boubenia et al. [5], as mentioned in Table 2, where the free charge density increases from $4.3 \times 10^{16}$ to $2 \times 10^{17} \mathrm{~cm}^{-3}$ as $\mathrm{NH}_{4} \mathrm{OH}$ concentration increases from 0 to $40 \mathrm{mM}$ in the growth solution. Therefore, we can hypothesize that the addition of $\mathrm{NH}_{4} \mathrm{OH}$ in the growth solution creates extra point defects in the $\mathrm{ZnO}$ NWs. Nevertheless, to confirm this hypothesis, we carried out another series of experiments where the as-grown $\mathrm{ZnO} \mathrm{NWs}$, without addition of $\mathrm{NH}_{4} \mathrm{OH}$, are treated in solution with increasing basicity. The details of the post-growth treatment experiments are given in Table 3.

The obtained experimental results for post-growth treatment of NWs in ammonia solution are shown in Figs. 3 and 4. Figure 3 shows the corresponding SEM images of the samples treated in different $\mathrm{NH}_{4} \mathrm{OH}$ concentrations. It can be seen, from the present set of data, that the NW's surface start to be rougher with increasing
$\mathrm{NH}_{4} \mathrm{OH}$ concentration, even leading to the formation of nano-hillock at the polar surface of $\mathrm{ZnO} \mathrm{NWs}$ for 100 and $200 \mathrm{mM}$ treated samples. The worst case can be seen for samples treated with 100 and $200 \mathrm{mM} \mathrm{NH}_{4} \mathrm{OH}$, where a few NWs seem to have broken from the base and are lying horizontally over the substrate. When further increasing the molarity of $\mathrm{NH}_{4} \mathrm{OH}$ solution, more than $90 \%$ of the NWs are broken (data not shown).

The resulting PL data arising from the post-growth treated samples are shown in Fig. 4. Figure 4a shows the PL spectra measured at RT for NWs treated with various ammonium hydroxide concentrations, whereas the extracted $\mathrm{I}_{\mathrm{UV}} / \mathrm{I}_{\mathrm{G}}$ plot is shown in Fig. 4b. It is to note that the peak position for both UV and visible emission has not been changed after $\mathrm{NH}_{4} \mathrm{OH}$ treatment, indicating that no extra point defect with different energy level is formed during the $\mathrm{NH}_{4} \mathrm{OH}$ treatment. The continuous reduction in the PL intensity of UV emission peak, with the increase of $\mathrm{NH}_{4} \mathrm{OH}$ concentration, clearly indicates the removal of $\mathrm{ZnO}$ nanomaterial due to a slow etching of the NWs in basic medium [46]. Furthermore, it is interesting to notice, from Fig. $4 \mathrm{~b}$, a clear and sharp decrease of the $\mathrm{I}_{\mathrm{UV}} / \mathrm{I}_{\mathrm{G}}$ ratio, as the NWs are treated in $\mathrm{NH}_{4} \mathrm{OH}$ solution. It is important to mention here that, for the present study, the experimental conditions such

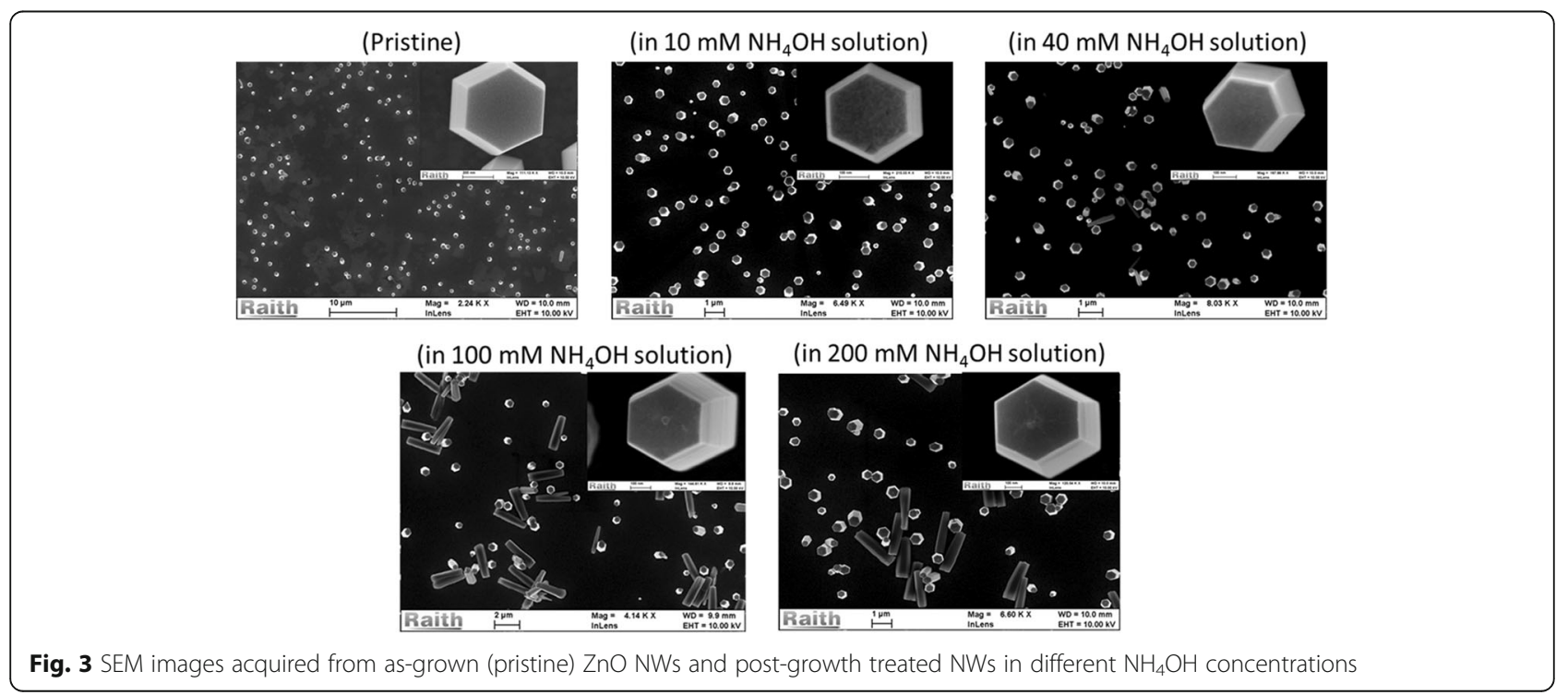



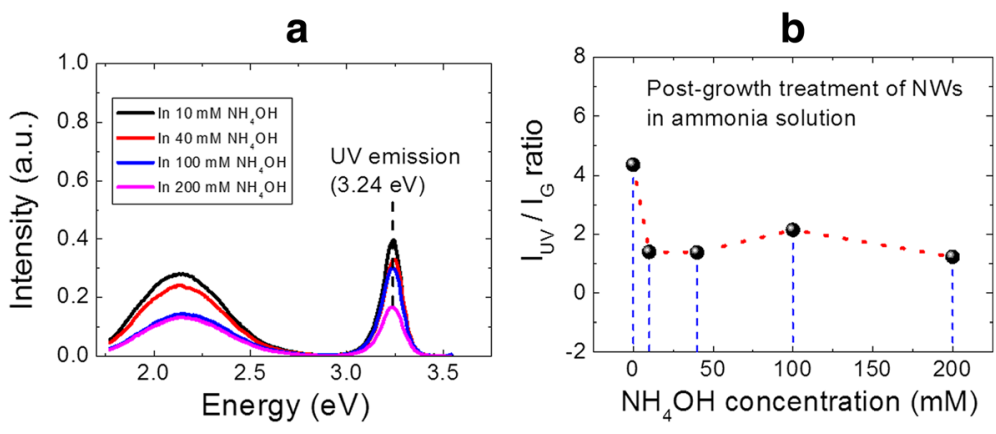

Fig. 4 a The PL spectra of the ZnO NWs treated in solutions with various ammonium hydroxide concentrations. $\mathbf{b}$ The intensity ratio of UV and green emission peaks as a function of $\mathrm{NH}_{4} \mathrm{OH}$ concentration, as extracted from a

as excitation density, radiation area, initial mass of $\mathrm{ZnO}$ nanomaterial, etc. are fixed. Therefore, the observed $\mathrm{I}_{\mathrm{UV}} / \mathrm{I}_{\mathrm{G}}$ ratio trend can be entirely related to the effect introduced by the addition of $\mathrm{NH}_{4} \mathrm{OH}$ and not to changes in experimental conditions [47]. The obtained experimental results clearly support the hypothesis made in the previous section for creation of extra point defects with the addition of $\mathrm{NH}_{4} \mathrm{OH}$ in the growth solution. We believe that the increase of growth solution basicity with the addition of $\mathrm{NH}_{4} \mathrm{OH}$ can slowly degrade the optical response of NWs by slowly etching its surfaces, which increases the level of point defects in $\mathrm{ZnO}$ NWs.

\section{Conclusions}

In summary, we demonstrated a facile, low-cost, and scalable bottom-up process for a seedless growth of $\mathrm{ZnO} \mathrm{NWs}$ on metallic $\mathrm{Au}$ surfaces. With a careful addition of ammonium hydroxide in the growth solution, $\mathrm{ZnO} \mathrm{NW}$ density can be controlled over two orders of magnitude. Consequences of the addition of $\mathrm{NH}_{4} \mathrm{OH}$ over the optical response of the obtained NWs were studied using photoluminescence technique. The visible emission spectrum, for each $\mathrm{NH}_{4} \mathrm{OH}$ concentration, was successfully deconvoluted to the blue, green, and orange defect states. Furthermore, percentage contribution of each defect state was also presented, showing the major contribution of visible emission was from green defect state. Thereby, to follow up the optical response of nanomaterial produced, we compared the intensity ratio of UV emission $\left(\mathrm{I}_{\mathrm{UV}}\right)$ to green defect state $\left(\mathrm{I}_{\mathrm{G}}\right)$. It was observed that the $\mathrm{I}_{\mathrm{UV}} / \mathrm{I}_{\mathrm{G}}$ ratio decreases sharply after the addition of $20 \mathrm{mM}$ of $\mathrm{NH}_{4} \mathrm{OH}$, hinting the creation of extra point defects with the addition of $\mathrm{NH}_{4} \mathrm{OH}$ in the growth solution. The experimental results were well supported by the literature data on the increase of free charge density with $\mathrm{NH}_{4} \mathrm{OH}$ addition. Nevertheless, the proposed hypothesis was further confirmed by performing another series of experiments where the as-grown $\mathrm{ZnO} \mathrm{NWs}$, without addition of $\mathrm{NH}_{4} \mathrm{OH}$, were treated in solutions with increasing basicity. A clear and sharp decrease of the $\mathrm{I}_{\mathrm{UV}} / \mathrm{I}_{\mathrm{G}}$ ratio, as the NWs were treated in $\mathrm{NH}_{4} \mathrm{OH}$ solution, showed that the increase of growth solution basicity with the addition of $\mathrm{NH}_{4} \mathrm{OH}$ can slowly degrade the optical response of NWs by etching its surfaces which increases the level of point defects in $\mathrm{ZnO} \mathrm{NWs}$. The present study is important to control the optical response of $\mathrm{ZnO} \mathrm{NWs}$ that can be directly grown on metallic $\mathrm{Au}$ electrodes for electronic and optoelectronic applications.

\section{Additional file}

Additional file 1: Figure S1. Raman spectroscopy acquired from ZnO NWs grown with different ammonium hydroxide concentrations. (DOCX 99 kb)

\section{Funding}

This project has received funding from the ECSEL $J U$ under grant agreement no. 692482. This JU receives support from the European Union's H2020 research and innovation programme and France, Netherlands, Denmark, Belgium, Germany, Czech Republic, and Spain. The authors are also grateful for the supports from Region Centre (MEPS project 2015-2018) and National Research Agency (ANR-14-CE08-0010-01).

\section{Availability of Data and Materials}

The datasets used and/or analyzed during the current study are available from the corresponding author on reasonable request.

\section{Authors' Contributions}

ASD and SB designed the experiments. ASD and SB performed the synthesis and structural/morphological analysis of the ZnO NWs. GF and SM performed the photoluminescence characterization. The drafting of the manuscript has been done by ASD. GF, GPV, SM, and DA did critical revisions of the manuscript. All authors have read and approved the final manuscript.

\section{Competing Interests}

The authors declare that they have no competing interests.

\section{Publisher's Note}

Springer Nature remains neutral with regard to jurisdictional claims in published maps and institutional affiliations.

\section{Author details}

${ }^{1}$ GREMAN UMR 7347 Université de Tours, CNRS, INSA Centre Val de Loire, 16 rue Pierre et Marie Curie, 37071 Tours CEDEX2, France. ${ }^{2}$ MATIS IMM-CNR and Dipartimento di Fisica e Astronomia, Universita' di Catania, via S. Sofia 64, 95123 Catania, Italy. ${ }^{3}$ GREMAN UMR 7347 CNRS, Université de Tours, INSA Centre Val de Loire, 3 rue de la Chocolaterie, CS 23410, 41034 Blois CEDEX, France. 
Received: 28 June 2018 Accepted: 9 August 2018 Published online: 22 August 2018

\section{References}

1. May BJ, Selcu CM, Sarwar ATMG, Myers RC (2018) Nanoscale current uniformity and injection efficiency of nanowire light emitting diodes. Appl Phys Lett 112:1-5. https://doi.org/10.1063/1.5020734

2. Gao F, Wen L, Xu Z et al (2017) Growth of InN nanowires with uniform diameter on $\mathrm{Si}$ (111) substrates: competition between migration and desorption of In atoms. Small 13:1-6. https://doi.org/10.1002/smll.201603775

3. $\mathrm{Xu} \mathrm{Z,} \mathrm{Yu} \mathrm{Y,} \mathrm{Han} \mathrm{J} \mathrm{et} \mathrm{al} \mathrm{(2017)} \mathrm{The} \mathrm{mechanism} \mathrm{of} \mathrm{indium-assisted} \mathrm{growth} \mathrm{of}$ (In) GaN nanorods: eliminating nanorod coalescence by indium-enhanced atomic migration. Nanoscale 9:16864-16870. https://doi.org/10.1039/ C7NR04555G

4. Dahiya AS, Morini F, Boubenia S et al (2018) Organic/Inorganic Hybrid Stretchable Piezoelectric Nanogenerators for Self-Powered Wearable Electronics. Adv Mat Tech 3:1700249. https://doi.org/10.1002/admt. 201700249

5. Boubenia S, Dahiya a S, Morini F et al (2017) A facile hydrothermal approach for the density tunable growth of $\mathrm{ZnO}$ nanowires and their electrical characterizations. Sci Rep 7:1-10. https://doi.org/10.1038/s41598017-15447-w

6. Pan ZW, Dai ZR, Wang ZL (2001) Nanobelts of semiconducting oxides. Science (80- ) 291:2000-2002

7. Könenkamp R, Nadarajah A, Word RC et al (2008) ZnO nanowires for LED and field-emission displays. J Soc Inf Disp 16:609-613. https://doi.org/10. $1889 / 1.2918081$

8. Lee CJ, Lee TJ, Lyu SC et al (2002) Field emission from well-aligned zinc oxide nanowires grown at low temperature. Appl Phys Lett 81:3648-3650. https://doi.org/10.1063/1.1518810

9. Yeom D, Keem K, Kang J et al (2008) NOT and NAND logic circuits composed of top-gate $\mathrm{ZnO}$ nanowire field-effect transistors with high-k Al (2) 0 (3) gate layers100 https://doi.org/10.1088/0957-4484/19/26/265202

10. Kälblein D, Weitz RT, Böttcher HJ et al (2011) Top-gate ZnO nanowire transistors and integrated circuits with ultrathin self-assembled monolayer gate dielectric. Nano Lett 11:5309-5315. https://doi.org/10.1021/nl202767h

11. Wang X, Zhou J, Song J et al (2006) Piezoelectric field effect transistor and nanoforce sensor based on a single ZnO nanowire. Nano Lett 6:2768-2772. https://doi.org/10.1021/nl061802g

12. Das SN, Kar JP, Choi J et al (2010) Fabrication and characterization of ZnO single nanowire-based hydrogen sensor. J Phys Chem C 114:1689-1693

13. Wang X, Summers CJ, Wang ZL (2004) Large-scale hexagonal-patterned growth of aligned ZnO nanorods for nano-optoelectronics and nanosensor arrays. Nano Lett 4:423-426. https://doi.org/10.1021/nl035102c

14. Djurišić $A B$, Chen $X$, Leung $Y H$, Man Ching Ng A (2012) ZnO nanostructures: growth, properties and applications. J Mater Chem 22:6526. https://doi.org/ 10.1039/c2jm15548f

15. Wang ZL (2004) Zinc oxide nanostructures: growth, properties and applications. J Phys Condens Matter 16:R829-R858. https://doi.org/10.1088/ 0953-8984/16/25/R01

16. Opoku C, Dahiya AS, Oshman C et al (2015) Fabrication of high performance field-effect transistors and practical Schottky contacts using hydrothermal ZnO nanowires. Nanotechnology 26:355704. https://doi.org/ 10.1088/0957-4484/26/35/355704

17. Opoku C, Dahiya a S, Cayrel F et al (2015) Fabrication of field-effect transistors and functional nanogenerators using hydrothermally grown $\mathrm{ZnO}$ nanowires. RSC Adv 5:69925-69931. https://doi.org/10.1039/C5RA11450K

18. Kushwaha A, Aslam M (2012) Defect induced high photocurrent in solution grown vertically aligned ZnO nanowire array films. J Appl Phys 112:1-8. https://doi.org/10.1063/1.4749808

19. Sohn Jl, Cha SN, Song BG et al (2013) Engineering of efficiency limiting free carriers and an interfacial energy barrier for an enhancing piezoelectric generation. Energy Environ Sci 6:97-104. https://doi.org/10.1039/ C2EE23404A

20. Kaps S, Bhowmick S, Gröttrup J et al (2017) Piezoresistive response of quasione-dimensional ZnO nanowires using an in situ electromechanical device. ACS Omega 2:2985-2993. https://doi.org/10.1021/acsomega.7b00041

21. Reimer T, Paulowicz I, Röder R et al (2014) Single step integration of ZnO Nano-and microneedles in Si trenches by novel flame transport approach: whispering gallery modes and photocatalytic properties. ACS Appl Mater Interfaces 6:7806-7815. https://doi.org/10.1021/am5010877

22. Mishra YK, Kaps S, Schuchardt A et al (2013) Fabrication of macroscopically flexible and highly porous 3D semiconductor networks from interpenetrating nanostructures by a simple flame transport approach. Part Part Syst Charact 30:775-783. https://doi.org/10.1002/ ppsc.201300197

23. Faraji N, Ulrich C, Wolff N et al (2016) Visible-light driven nanoscale photoconductivity of grain boundaries in self-supported ZnO Nano- and microstructured platelets. Adv Electron Mater 2:1-7. https://doi.org/10.1002/ aelm.201600138

24. Dahiya AS, Opoku C, Alquier D et al (2014) Controlled growth of 1D and 2D ZnO nanostructures on 4H-SiC using Au catalyst. Nanoscale Res Lett 9:379. https://doi.org/10.1186/1556-276X-9-379

25. Yin Z, Wu S, Zhou X et al (2010) Electrochemical deposition of ZnO nanorods on transparent reduced graphene oxide electrodes for hybrid solar cells. Small 6:307-312. https://doi.org/10.1002/smll.200901968

26. Hu Y, Lin L, Zhang Y, Wang ZL (2012) Replacing a battery by a nanogenerator with $20 \mathrm{~V}$ output. Adv Mater 24:110-114. https://doi.org/10. 1002/adma.201103727

27. Greene LE, Yuhas BD, Law M et al (2006) Solution-grown zinc oxide nanowires. Inorg Chem 45:7535-7543. https://doi.org/10.1021/ic0601900

28. Richardson JJ, Lange FF (2009) Controlling low temperature aqueous synthesis of ZnO. 2. A novel continuous circulation reactor. Cryst Growth Des 9:2570-2575. https://doi.org/10.1021/la8006348

29. Zhu G, Wang AC, Liu Y et al (2012) Functional electrical stimulation by nanogenerator with $58 \mathrm{~V}$ output voltage. Nano Lett 12:3086-3090. https:// doi.org/10.1021/nl300972f

30. Zheng N, Huang Y, Sun W et al (2016) In-situ pull-off of ZnO nanowire from carbon fiber and improvement of interlaminar toughness of hierarchical ZnO nanowire/carbon fiber hydrid composite laminates. Carbon N Y 110: 69-78. https://doi.org/10.1016/j.carbon.2016.09.002

31. Tam KH, Cheung CK, Leung YH et al (2006) Defects in ZnO nanorods prepared by a hydrothermal method. J Phys Chem B 110:20865-20871. https://doi.org/10.1021/jp063239w

32. Janotti A, Van De Walle CG (2007) Native point defects in ZnO. Phys Rev B Condens Matter Mater Phys 76:1-22. https://doi.org/10.1103/PhysREevB.76. 165202

33. Barbagiovanni EG, Strano V, Franzò G et al (2016) Universal model for defect-related visible luminescence in $\mathrm{ZnO}$ nanorods. Rsc Adv 6:7317073175. https://doi.org/10.1039/C6RA14453E

34. Djurišić AB, Choy WCH, Roy VAL et al (2004) Photoluminescence and electron paramagnetic resonance of $\mathrm{ZnO}$ tetrapod structures. Adv Funct Mater 14:856-864. https://doi.org/10.1002/adfm.200305082

35. Alenezi MR, Henley SJ, Silva SRP (2015) On-chip fabrication of high performance nanostructured ZnO UV detectors. Sci Rep 5:8516. https://doi. org/10.1038/srep08516

36. Tian J-H, Hu J, Li S-S et al (2011) Improved seedless hydrothermal synthesis of dense and ultralong ZnO nanowires. Nanotechnology 22:245601. https:// doi.org/10.1088/0957-4484/22/24/245601

37. Wang L, Giles NC (2003) Temperature dependence of the free-exciton transition energy in zinc oxide by photoluminescence excitation spectroscopy. J Appl Phys 94:973-978. https://doi.org/10.1063/1.1586977

38. Zhang BP, Binh NT, Segawa Y et al (2004) Photoluminescence study of ZnO nanorods epitaxially grown on sapphire (1120) substrates. Appl Phys Lett 84 586-588. https://doi.org/10.1063/1.1642755

39. Peng WQ, Qu SC, Cong GW, Wang ZG (2006) Synthesis and temperaturedependent near-band-edge emission of chain-like Mg-doped $\mathrm{ZnO}$ nanoparticles. Appl Phys Lett 88:101902. https://doi.org/10.1063/1.2182010

40. Hsu HC, Tseng YK, Cheng HM et al (2004) Selective growth of ZnO nanorods on pre-coated ZnO buffer layer. J Cryst Growth 261:520-525. https://doi.org/10.1016/j.jcrysgro.2003.09.040

41. Park Wl, Jun YH, Jung SW, Yi GC (2003) Excitonic emissions observed in ZnO single crystal nanorods. Appl Phys Lett 82:964-966. https:/doi.org/10.1063/1. 1544437

42. Kim S, Park H, Nam G et al (2013) Temperature-dependent photoluminescence of boron-doped ZnO nanorods. Bull Kor Chem Soc 34: 3335-3339. https://doi.org/10.5012/bkcs.2013.34.11.3335

43. Barbagiovanni EG, Reitano R, Franzò G et al (2016) Radiative mechanism and surface modification of four visible deep level defect states in $\mathrm{ZnO}$ nanorods. Nanoscale 8:995-1006. https://doi.org/10.1039/C5NR05122C 
44. Cheng B, Shi W, Russell-tanner JM et al (2006) Synthesis of variable-aspectratio, single-crystalline ZnO nanostructures. Inorg Chem 45:1208-1214

45. Chen LY, Yin YT, Chen CH, Chiou JW (2011) Influence of polyethyleneimine and ammonium on the growth of $\mathrm{ZnO}$ nanowires by hydrothermal method. J Phys Chem C 115:20913-20919. https://doi.org/10.1021/ jp2056199

46. Zhou J, Xu NS, Wang ZL (2006) Dissolving behavior and stability of ZnO wires in biofluids: a study on biodegradability and biocompatibility of $\mathrm{ZnO}$ nanostructures. Adv Mater 18:2432-2435. https://doi.org/10.1002/adma. 200600200

47. Shi WS, Cheng B, Zhang L, Samulski ET (2005) Influence of excitation density on photoluminescence of zinc oxide with different morphologies and dimensions. J Appl Phys 98:083502. https://doi.org/10.1063/1.2089160

\section{Submit your manuscript to a SpringerOpen ${ }^{\odot}$ journal and benefit from:}

- Convenient online submission

- Rigorous peer review

- Open access: articles freely available online

- High visibility within the field

- Retaining the copyright to your article

Submit your next manuscript at $\boldsymbol{\nabla}$ springeropen.com 